\title{
HUBUNGAN ANTARA PENDIDIKAN DAN SUMBER INFORMASI DENGAN TINGKAT PENGETAHUAN IBU TENTANG POST PARTUM BLUES DI RB RATNA KOMALA BEKASI JAWA BARAT TAHUN 2013
}

\author{
Rini Kundaryanti ${ }^{1}$ \\ Rukmaini $^{2}$ \\ Mutiara $^{3}$ \\ Dosen D4 Kebidanan Fikes UNAS Jakarta ${ }^{1,2}$, Alumni D4 Fikes UNAS Jakarta ${ }^{3}$ \\ Jl. sawo manila pejaten ps minggu jakarta ${ }^{1,2,3}$ \\ Email: rinik74@gmail.com ${ }^{I)}$,
}

\begin{abstract}
ABSTRAK
Morbilitas dan mortalitas pada bayi tentunya sangat erat sekali hubungannya dengan kondisi ibu baik selama kehamilan maupun setelah melahirkan dan selama merawat bayinya. Untuk dapat merawat bayinya dengan baik maka dibutuhkan seorang ibu yang sehat baik fisik maupun keadaan jiwanya, seorang ibu yang mengalami gangguan psikologi/jiwa tentunya mereka tidak dapat merawat bayinya dengan baik sehingga dapat menyokong meningkatnya jumlah kesakitan dan kematian pada bayi. Angka Kematian Bayi (AKB) Provinsi Jawa Barat selama kurun waktu tahun 2005 hingga tahun 2008 mengalami penurunan, pada tahun 2005 AKB Provinsi Jawa Barat sebesar 40,87 per 1.000 kelahiran hidup dan pada tahun 2008 sebesar 38,51 per 1.000 kelahiran hidup, namun angka Kematian Bayi Provinsi Jawa Barat di tahun 2008 masih diatas angka kematian bayi nasional yang mencapai 34 per 1.000 kelahiran hidup dan angka kematian bayi Provinsi Jawa Barat pada tahun 2008 tersebut juga masih sangat jauh dari target pencapaian MDGs, yang menargetkan AKB di Indonesia sebesar 19 per 1000 kelahiran hidup pada tahun 2015. Metode Penelitian ini menggunakan rancangan study cross sectional dari data primer. Alat pengumpul data berupa kuesioner dengan populasi ibu post partum dengan jumlah sampel 50 responden, analisis data menggunakan analisis univariat dan bivariat. Hasil dari penelitian ini menyatakan bahwa pengetahuan ibu yang baik tentang post partum blues paling banyak pada responden yang berpendidikan tinggi yaitu sebesar 75,0\% yang mendapatkan sumber informasi langsung dari tenaga kesehatan yaitu sebanyakn 57,9\%. Simpulan yang diperoleh adalah adanya hubungan yang signifikan antara pendidikan dan sumber informasi dengan pengetahuan ibu nifas tentang post partum blues.
\end{abstract}

Kata Kunci : pendidikan, pengetahuan, post partum blues

\section{PENDAHULUAN}

Angka Kematian Bayi (AKB) di Indonesia masih tergolong tinggi jika dibandingkan dengan negara lain di kawasan ASEAN. Berdasarkan Human Development Report 2010, AKB di Indonesia mencapai 31 per 1.000 kelahiran. Angka Kematian Bayi (AKB) merupakan salah satu indikator sosial yang sangat penting untuk mengukur status kesehatan ibu dan anak (Kosim, 2003). Menurut BKKBN tahun 2010 Angka Kematian Ibu (AKI) tercatat sebanyak 228 per 100.000 kelahiran hidup dan Angka
Kematian Bayi (AKB) 34 per 1.000 kelahiran hidup. Sedangkan menurut Survei Demografi Kesehatan Indonesia tahun 2010 Angka Kematian Ibu (AKI) di Indonesia adalah 307 per 100.000 kelahiran hidup, sedangkan Angka Kematian Bayi (AKB) sebesar 35 per 1.000 kelahiran hidup.

Dalam rangka pencapaian sasaran Milenium Development Goals (MDGs) yaitu Angka Kematian Ibu (AKI) sebesar 102 per 100.000 Kelahiran Hidup (KH) dan Angka Kematian Bayi (AKB) menjadi 23 per 1.000 Kelahiran Hidup $(\mathrm{KH})$ pada tahun 2015, maka diperlukan upaya 
percepatan yang lebih besar dan kerja keras. Morbilitas dan mortalitas pada bayi tentunya sangat erat sekali hubungannya dengan kondisi ibu baik selama kehamilan maupun setelah melahirkan dan selama merawat bayinya. Untuk dapat merawat bayinya dengan baik maka dibutuhkan seorang ibu yang sehat baik fisik maupun keadaan jiwanya, seorang ibu yang mengalami gangguan psikologi / jiwa tentunya mereka tidak dapat merawat bayinya dengan baik sehingga dapat menyokong meningkatnya jumlah kesakitan dan kematian pada bayi.

\section{Angka Kematian Bayi (AKB)} Provinsi Jawa Barat selama kurun waktu tahun 2005 hingga tahun 2008 mengalami penurunan, pada tahun 2005 AKB Provinsi Jawa Barat sebesar 40,87 per 1.000 kelahiran hidup dan pada tahun 2008 sebesar 38,51 per 1.000 kelahiran hidup, namun angka Kematian Bayi Provinsi Jawa Barat di tahun 2008 masih diatas angka kematian bayi nasional yang mencapai 34 per 1.000 kelahiran hidup dan angka kematian bayi Provinsi Jawa Barat pada tahun 2008 tersebut juga masih sangat jauh dari target pencapaian MDGs, yang menargetkan AKB di Indonesia sebesar 19 per 1000 kelahiran hidup pada tahun 2015 (Sirait, 2010). Angka Kematian Bayi di Kota Bekasi masih tinggi, mencapai 37 bayi dari setiap 1.000 bayi yang lahir. Menurut Dinas Kesehatan Kota Bekasi pada Tahun 2009, Angka Kematian Bayi (AKB) sebanyak 84 kasus, sedangkan pada tahun 2010 Angka Kematian Bayi (AKB) sebanyak 59 kasus, berdasarkan AKB tahun 2009 sampai 2010 mengalami penurunan (Dinas Kota Bekasi, 2010). Umumnya wanita merasakan kebahagiaan ketika hamil, namun kegembiaraan itu berganti tanpa sebab justru setelah bayi dilahirkan, mungkin ini disebabkan oleh karena, beberapa penyesuaian yang dibutuhkan ibu pada minggu-minggu pertama atau bulan pertama setelah melahirkan baik dari segi fisik maupuk segi psikologis, sebagian wanita berhasil menyesuaikan diri dengan baik tetap sebagian lain tidak berhasil menyesuaikan diri dan mengalami ganggguan psikologis dengan berbagai gejala atau syndrome dimana para klinisi menyebutkan keadaan " Post - Partum Blues " / Baby Blues / Maternity Blues (Iskandar. S, 2007). Dalam dekade terakhir ini, banyak peneliti dan klinisi yang memberi perhatian khusus pada gejala psikologis yang menyertai seorang wanita pasca bersalin, dan telah melaporkan beberapa angka kejadian dan berbagai faktor yang diduga mempunyai kaitan dengan gejala-gejala post partum blues, berbagai studi mengenai post partum blues dari tahun 1983 - 1990 di luar negri (Amerika, Belanda, Swedia, Australia, dll) melaporkan angka kejadian post partum blues cukup tinggi yaitu $76 \%$, di Itali pada tahun 1990 sebesar $42-76 \%$. Jumlah yang bervariasi ini memungkinkan disebabkan karena adanya perbadaan populasi dan criteria diagnosis yang digunakan (O'Hara dalam Ismail, dkk, 2002).

Di Indonesia kegiatan mendeteksi adanya gangguan post-partum blues psikologis belum merupakan acuan pelayanan pasca salin, karena masalah ini dikategorikan sebagai sindrom gangguan mental yang ringan oleh sebab itu sering tidak dipedulikan sehingga tidak terdiagnosis dan tidak ditatalaksanakan sebagaimana seharusnya.

Pada akhirnya postpartum blues dapat menjadi masalah yang menyulitkan, dan bahkan dapat berkembang menjadi keadaan yang lebih berat yaitu depresi dan dan psikosis post partum yang mempunyai dampak lebih buruk terutama untuk kelangunan hidup, pertumbuhan dan perkembangan anaknya (Iskandar, 2006), sehingga anak bisa tumbuh menjadi anak yang mudah menangis, cendrung rewel, pencemas sekaligus pemurung. Dampak lain yang tidak kalah merugikan adalah : si anak mudah cendrung mudah sakit dan 
menyokong semakin bertambahnya Angka Kesakitan Bayi dan Angka Kematian Bayi. Depresi ibu yang tidak tertangani dengan baik dan berpengaruh pada perkembangan fisik dan mental anak setidaknya sampai si anak berusia 6 tahun (Syamil, dkk, 2007).

Menurut Ismail Irawati (2002) dalam disertasinya menyebutkan, angka kejadian depresi Antepartum 18\% yang berlanjut ke post-partum blues mencapai $60 \%$ dan berlanjut ke depresi post partum $50 \%$. Dari hasil penelitian di ruang bersalin RSU Dr. Soetomo Surabaya tahun 2006 ditemukan 54,84\% mengalami postpartum blues dimana penyebabnya $38,7 \%$ dari pengalaman dalam proses kehamilan dan persalinananya, 19,35\% kurangnya dukungan sosial dari lingkungan, 16,3\% kualitas bayi yang di lahirkan dan 9,78\% dari faktor spiritual.

Hasil penelitian di RSHS Bandung oleh Wratsangka (1996) menunjukan proporsi sebesar $29,6 \%$ ibu yang mengalami postpartum blues pada populasi yang tidak memperhatikan tingkat pendidikan atau pekerjaan sampel, sedangkan setelah dilihat dari proses kelahiran spontan, ditemukan $33 \%$ mengalami post-partum blues.

Penelitian lain di Jakarta menunjukan angka kejadian post-partum blues 28,8\% (Ismail Irawati, 2002). Sedangkan menurut susilowati (2001) faktor-faktor yang berhubungan gangguan psikologis masa nifas adalah umur ibu $\geq$ 30 tahun mempunyai resiko 5,07 kali umur 20 - 35 tahun dan umur $\leq 20$ tahun lebih beresiko 4,65 kali dari umur 20 - 30 tahun, status sosial ekonomi rendah lebih beresiko terjadinya gangguan psikologis 2,88 kali dibandingkan dengan ibu yang sosial ekonominya cukup, dukungan sosial kurang, beresiko tejadi DPP 2,66 kali dari ibu yang dukungan social cukup. Gangguan non psikotik pada periode pasca persalinan cukup tinggi, penelitian menunjukan $20-40 \%$ wanita hamil mengalami gangguan emosi dan disfungsi kognitif, ataupun kedua-duanya. Angka kejadian psikosis pasca persalinan adalah 1-2 per 1.000 kelahiran dari seluruh wanita pasca persalinan, dan angka kejadian postpartum blues adalah $50-70 \%$ dari wanita pasca persalinan dari latar belakang diatas penulis ingin melihat hubungan antara pendidikan dan sumber informasi dengan kejadian post partum blues di BPS Ratna Komala S.S.T Bekasi Jawa Barat.

\section{METODE}

Jenis penelitian ini menggunakan rancangan cross sectional. Populasi pada penelitian ini adalah seluruh ibu post partum di RB Ratna Komala April Tahun 2013. Sedangkan sampel pada penelitian ini adalah ibu post partum dimana pada saat penelitian berlangsung masih dalam masa nifas dan bersedia menjadi responden. Penelitian ini dilaksanakan pada bulan April 2013 sampai bulan Juni 2013. Sumber data yang digunakan dalam penelitian ini adalah data primer yaitu data yang diperoleh melalui pengumpulan secara langsung oleh peneliti terhadap responden dengan menggunakan kuesioner dan wawancara. Data diolah dengan SPSS 17. Tehnik analisis data dalam penelitian ini dilakukan secara bertahap meliputi: analisi univariat untuk menghitung distribusi frekuensi dan analisi bivariat untuk melihat apakah ada hubungan antara variable dependent dengan variable independent, denngan menggunakan uji Chi Sguare.

Uji Chi Sguare merupakan uji statistic non parametric untuk melihat hubungan dua buah variable nominal atau antara variable nominal dengan ordinal. Dalam penelitian ini uji Chi Sguare digunakan untuk melihat hubungan antara pendidikan dan sumber informasi dengan tingkat pengetahuan ibu tentang post partum blues. Dari uji ini akan di dapatkan hasil: Ho diterima atau Ha ditolak bila $\mathrm{p}$ value $>$ nilai $\alpha=0,05$, artinya tidak ada hubungan yang bermakna. Dan jika Ho ditolak atau Ha diterima bila $\mathrm{p}$ value $\leq$ 
nilai $\alpha=0,05$, artinya ada hubungan yang bermakna.

\section{HASIL DAN PEMBAHASAN}

Analisis dilakukan untuk melihat hubungan antara masing-masing variabel independent dan variabel dependent mengenai hubungan antara pendidikan dan sumber informasi dengan tingkat pengetahuan ibu tentang post partum blues di RB Ratna Komala Bekasi Jawa Barat tahun 2013 dengan sampel sebanyak 50 responden.

\section{Hubungan Antara Pendidikan dengan Tingkat Pengetahuan Ibu tentang Post Partum Blues di RB Ratna Komala Bekasi tahun 2013}

\begin{tabular}{|c|c|c|c|c|c|c|c|}
\hline \multicolumn{7}{|c|}{ Pengetahuan Ibu Post Partum } \\
\hline Pendidikan & \multicolumn{2}{|c|}{ Baik } & \multicolumn{2}{c|}{ Kurang } & \multicolumn{2}{c|}{ Total } & P - value \\
\hline & n & \% & n & \% & n & $\%$ & \\
\hline Rendah & 11 & 28,9 & 27 & 71,1 & 38 & 100 & 0,005 \\
\hline Tinggi & 9 & 75,0 & 3 & 25,0 & 12 & 100 & \\
\hline Total & 20 & 40,0 & 30 & 60,0 & 50 & 100 & OR $=7,364$ \\
\hline
\end{tabular}

Hasil analisa hubungan antara pendidikan terhadap pengetahuan ibu tentang post partum blues berdasarkan tabel di atas diperoleh hasil bahwa pengetahuan ibu post partum yang baik paling banyak pada responden yang berpendidikan tinggi yaitu sebanyak 9 responden $(75,0 \%)$ dibandingkan dengan ibu yang berpendidikan rendah yaitu sebanyak 11 responden $(28,9 \%)$. Sedangkan pengetahuan ibu post partum yang kurang paling banyak pada responden yangberpendidikan rendah yaitu sebanyak 27 responden $(71,1 \%)$ dibandingkan dengan ibu yang berpendidikan tinggi yaitu sebanyak 3 responden $(25,0 \%)$. Hasil uji statistik chi square diperoleh nilai pvalue $0,005<\alpha(0,05)$, maka dapat disimpulkan ada hubungan yang signifikan antara pengetahuan ibu hamil dengan pendidikan dengan nilai $\mathrm{OR}=7,364$ (OR > 1) yang artinya ibu pendidikan tinggi berpeluang 7,364 lebih besar untuk mempunyai pengetahuan yang baik.

Hal ini sejalan dengan Penelitian Resna (1999) bahwa pendidikan SD atau pendidikan rendah menunjukan prestasi tertinggi terjadinya post partum blues yaitu sebesar 53,84\%, sebagian besar latar belakang pendidikan penderita post partum blues adalah yang berpendidikan rendah. Demikian pula pada hasil penelitian Susilowati memperlihatkan secara proporsi ibu yang berpendidikan rendah lebih banyak yang mengalami depresi post partum blues. Hal ini sesuai dengan teori yang menyebutkan Pendidikan adalah aktifitas belajar yang memberikan tambahan ilmu pengetahuan, ketrampilan serta dapat mempengaruhi proses berfikir secara sistematis dimana pendidikan tersebut bukan hanya transfer informasi pengetahuan tetapi juga merupakan suatu seni yang dapat membentuk keteraturan sikap dan segala budaya manusia (Notoatmodjo.S 2010).

Menurut Kamus Besar Bahasa Indonesia (2007) pendidikan adalah proses pengubah sikap dan tata laku seseorang atau kelompok orang dalam usaha mendewasakan manusia melalui upaya pengajaran dan pelatihan, proses, pembuatan cara mendidik. Pendidikan 
adalah upaya persuasi atau pembelajaran kepada masyarakat agara masyarakat ingin melakukan tindakan-tindakan (praktik) untuk memelihara (mengatasi masalahmasalah) dan meningkatkan kesehatannya (Notoatmodjo, 2010). Menurut Peneliti bahwa pendidikan sangat berpengaruh terhadap pengetahuan ibu tentang post partum blues, apabila ibu yang mempunyai pendidikan tinggi maka akan lebih banyak mengetahui tentang pengetahuan sehingga bisa mencegah post partum blues.

\section{Hubungan Antara Sumber Informasi dengan Tingkat Pengetahuan Ibu tentang Post Partum Blues di RB Ratna Komala Bekasi tahun 2013}

\begin{tabular}{|l|c|c|c|c|c|c|c|}
\hline \multicolumn{7}{|c|}{ Pengetahuan Ibu Post Partum } \\
\hline Sumber Informasi & \multicolumn{2}{|c|}{ Baik } & \multicolumn{2}{c|}{ Kurang } & \multicolumn{2}{c|}{ Total } & P - Value \\
\hline & n & \% & n & \% & n & \% & \\
\hline Langsung (Nakes) & 11 & 57,9 & 8 & 42,1 & 19 & 100 & 0,043 \\
\hline $\begin{array}{l}\text { Tidak Langsung Non } \\
\text { Nakes }\end{array}$ & 9 & 29,0 & 22 & 71,0 & 31 & 100 & \\
\hline Total & 20 & 40,0 & & 60,0 & 50 & 100 & OR $=0,298$ \\
\hline
\end{tabular}

Hasil analisa hubungan antara sumber informasi terhadap pengetahuan ibu tentang post partum blues berdasarkan table di atas di peroleh hasil bahwa pengetahuan ibu post partum yang baik paling banyak pada responden yang mendapatkan sumber informasi langsung dari tenaga kesehatan yaitu sebanyak 11 responden $(57,9 \%)$ dibandingkan dengan ibu yang mendapatkan sumber informasi tidak langsung dari tenaga kesehatan yaitu sebanyak 9 responden $(29,0 \%)$. Sedangkan pengetahuan ibu post partum yang kurang paling banyak pada responden yangmendapatkan sumber informasi tidak langsung dari tenaga kesehatan yaitu sebanyak 22 responden $(71,0 \%)$ dibandingkan dengan ibu yang mendapatkan sumber informasi langsung dari tenaga kesehatan yaitu sebanyak 8 responden $(42,1 \%)$. Hasil uji statistik chi square diperoleh nilai $\mathrm{p}$ value $0,043<\alpha$ $(0,05)$, maka dapat disimpulkan ada hubungan yang signifikan antara pengetahuan ibu post partum dengan sumber informasi dengan nilai $\mathrm{OR}=$ 0,928 . Hal ini sejalan dengan penelitian yang dilakukan Suyono (1998), semakin sering seseorang memperoleh informasi, semakin banyak pula pengetahuan yang dimiliki.

Menurut penelitin Siti Haeriyah (2009), mengemukakan seseorang akan mengetahui seseuatu apabila ia memperolehnya dari suatu sumber yang berada di sekitarnya. Menurut penelitian Yuli Catur Putri (2012), sumber informasi adalah sesuatu yang menjadi perantara dalam menyampaikan informasi, merangsang pikiran dan kemampuan, informasi yang diperoleh dalam menyampaikan informasi yang diperoleh dari berbagai sumber akan mempengaruhi tingkat pengetahuan seseorang. Bila seseorang memperoleh informasi, maka cendrung mempunyai pengetahuan yang lebih luas. Menurut penelitian Suyono (1998), semakin sering seseorang memperoleh informasi, semakin banyak pula pengetahuan yang dimiliki.

Menurut Notoatmodjo (2007), sumber informasi kesehatan diperoleh dari media, karena media merupakan saluran (channel) untuk penyampaian informasi kesehatan bagi masyarakat atau klien. Menurut Peneliti, Sumber informasi yang di dapat oleh ibu tentang 
post partum blues akan lebih baik apabila petugas tenaga kesehatan memberikan penyuluhan kesehatan kepada ibu dan saling bekerjasama dengan baik, sumber informasi tidak hanya dari tenaga kesehatan yakni bisa melalui sarana telekomunikasi seperti radio, televisi/video, artikel majalah/ surat kabar yang merupakan sumber informasi yang dapat meningkatkan pengetahuan ibu, sehingga sumber informasi merupakan faktor yang berhubungan dengan tingkat pengetahaun ibu tentang post partum blues.

\section{KESIMPULAN}

Pengetahuan ibu tentang post partum blues sangat berhubungan dengan pendidikan dan sumber informasi, sehingga perlu lebih ditingkatkan lagi peran serta tenaga kesehatan dalam memberikan konseling pada ibu hamil dan nifas sehingga kasus post partum blues dapat berkurang.

\section{DAFTAR PUSTAKA}

[1] Dewi M, S.ST, MKes, 2012. Asuhan Kebidanan Nifas Dan Menyusui. Pustaka, Pelajar : Yogyakarta.

[2] Irianti, I. 2010. Psikologi Untuk MahasiswaKebidanan. EGC:Jakarta

[3] Jhaquin, A. 2010.Psikologi Untuk Kebidanan. Nuha Medika : Yogyakarta

[4] Mochtar, R. 1998. Sinopsis Obstetri.EGC : Jakarta

[5] Notoadmodjo, S. 2003. Pendidikan dan Perilaku Kesehatan. Jakarta :

[6] Notoadmodjo, S. 2007.Kesehatan Masyarakat Ilmu dan Seni. Jakarta :
[7] Notoatmodjo, S. 2010. Metode Penelitian Kesehatan. RinekaCipta : Jakarta.

[8] Nursalam. 2008. Konsep dan Penerapan Metodologi Penelitian Ilmu Keperawatan. Salemba Medika : Jakarta

[9] Prawirohardjo, S. 2009. Ilmu Kebidanan. Jakarta : YBP-SP.

[10] Riwidikdo, H. 2009. Statistik untuk Penelitian Kesehatan dengan Aplikasi Program $R$ dan SPSS. Yogyakarta :Pustaka Rihama.

[11] Salehah, S. 2002. Asuhan Kebidanan PadaMasa Nifas. Salemba Medika : Jakarta

[12] Sayogo, S. 2008. Majalah Kesehatan Kedokteran Indonesia Vol.V No. 10.

[13] Suherni, S. Pd, APP, M.Kes. Hesty Widyasih, SST. Anita Rahmawati, SST, 2009. Perawatan masa nifas. Fitramaya : Yogyakarta.

[14] Sraight. Barbara, R. 2002. Keperawatan Ibu dan Bayi Baru Lahir. EGC: Jakarta

[15] Sulistyawati, A. 2011.Asuhan Kebidanan pada Masa Kehamilan. Jakarta : Salemba Medika.

[16] Suherni. 2009. Perawatan Masa Nifas. Fitramaya: Yogyakarta

[17] Syafrudin, Karningsing, dan Mardiana. 2011. Untaian Materi Penyuluhan KIA (Kesehatan Ibu dan Anak). Jakarta : TIM. 
[18] Vivian NLD, Tri S, 2011. Asuhan Kebidanan Pada Ibu Nifas. Salemba Medika : Jakarta.

[19]Wiknjosastro, H. 2002. Ilmu Kandungan. Jakarta: Yayasan Bina Pustaka Sarwono, Prawirohardjo. 